\title{
Validation of an asthma quality of life diary in a clinical trial
}

\author{
M E Hyland, G R Crocker
}

\begin{abstract}
Background - Quality of life (QOL) is commonly measured in asthma clinical trials by a questionnaire given before and after treatment. A structured asthma QOL daily diary provides more restricted information but on a daily basis. The validity and use of such a QOL diary was examined in a clinical trial in which two asthma treatments were compared.
\end{abstract}

Methods - The effects of low dose inhaled steroid (400 $\mu \mathrm{g}$ beclomethasone dipropionate, BDP) combined with the long acting $\beta_{2}$ agonist salmeterol $(100 \mu \mathrm{g})(\mathrm{n}=$ 220) was compared with high dose inhaled steroid $(1000 \mu \mathrm{g}$ BDP) $(n=206)$ in asthmatic outpatients in a double blind, parallel group study. Outcome measures consisted of a combined diary for peak expiratory flow (PEF) rate, symptoms, and problems, and an asthma-specific QOL questionnaire, the Living with Asthma Questionnaire.

Results - The QOL diary correlated with the QOL questionnaire for both cross sectional and longitudinal assessments. Cross sectional correlations with PEF were higher for the QOL questionnaire than the QOL diary, but longitudinal correlations with PEF were higher for the diary than the questionnaire. Treatment with low dose steroid/salmeterol compared with high dose steroid produced better lung function, better QOL as measured by diary, and reduced night time wakenings, but treatment differences were not obtained with the QOL questionnaire nor for daytime symptoms. Diary assessed QOL was a better predictor of low PEF than diary assessed symptoms. Compliance with diary completion was good but there were floor or ceiling effects in the QOL diary records of about $25 \%$ of patients.

Department of Psychology $M$ E Hyland

School of Mathematics and Statistics G R Crocker

University of Plymouth, Plymouth PL4 8AA, UK

Reprint requests to: Dr M Hyland.

Received 20 October 1994 Returned to authors 5 December 1994 Revised version received 20 February 1995 Accepted for publication 23 March 1995 flow graph, while symptoms are more widely distributed with respect to peak flow.

(Thorax 1995;50:724-730)

Keywords: quality of life, asthma, diary, validation.
Four asthma-specific quality of life (QOL) questionnaires $^{1-4}$ and one life activity checklist ${ }^{5}$ have been published, all of which have been designed to measure QOL in clinical trials and all of which have acceptable validity. Each of these instruments requires patients to indicate how much they have been affected by asthma over a time span varying between two weeks and one year. However, asthma symptoms are also measured through the use of daily symptom diaries and, given the widespread use of diaries in asthma clinical trials, it would be feasible to measure some of the QOL deficits associated with asthma on a daily basis. Other research shows that the questionnaire assessment of life events introduces recall errors which increase with duration between event and recording, ${ }^{6}$ and in some circumstances diary assessments can be superior. ${ }^{7}$ This study examines the validity of an asthma-specific, structured QOL diary as an outcome measure in clinical trials.

Asthma can affect patients' QOL in many different ways. Thus, some patients may experience specific problems resulting from exacerbations of symptons during certain activities and be distressed either by the symptoms themselves or by the immediate loss or reduction of participation in activity that they cause. Other patients may then choose to avoid activities that they think are likely to cause exacerbations, and thus experience distress at missing out on the activity altogether. While questionnaires can measure all these different aspects of QOL deficit, diaries relate best to the first aspect - namely, specific problems that arise from exacerbations of symptoms. QOL diaries are therefore not a substitute for QOL questionnaires as they measure only one component of QOL.

Responsiveness to longitudinal change is a primary characteristic of any clinical trial tool ${ }^{89}$ Of the many measurable aspects of QOL, some seem less likely to change in a clinical trial than others, because clinical trials measure over only a relatively short period of a patient's life. If a patient adopts an avoidant coping strategy for activities that cause asthma problems, this strategy may not change for some time even after the patient's asthma has become better controlled. Similarly, the distress caused by asthma may still occur for a period after asthma has become well controlled due to patient's recall of prior asthma events. By contrast, the frequency with which the patient has specific, exacerbationinduced problems is likely to change more rapidly with better control of asthma. The type of QOL deficit measured by a diary is therefore more likely to be responsive to change com- 
pared with other deficits that are also included in QOL questionnaires. ${ }^{10}$

In this study we examined the responsiveness of a structured QOL diary by comparing the ability of a diary and questionnaire to detect treatment differences. In addition, we examined the cross sectional and longitudinal correlations between the QOL diary, questionnaire, diary measured symptoms, and daily peak expiratory flow (PEF) to provide information about the validity of QOL diary methodology.

\section{Methods}

STUDY DESIGN

This multicentre, double blind, parallel group study compared two treatment regimens: beclomethasone dipropionate (BDP) $400 \mu \mathrm{g}$ daily plus salmeterol xinafoate $100 \mu \mathrm{g}$ versus BDP $1000 \mu \mathrm{g}$ daily. Patients were initially assessed over a two week baseline period during which they took BDP $400 \mu \mathrm{g}$ daily. On successful completion of the baseline, patients were randomly allocated to one of the two treatment groups over a six month period from which we report data for the first three months.

\section{PATIENT SELECTION}

Patients aged between 18 and 75 were admitted into the baseline period if they were receiving $400 \mu \mathrm{g}$ BDP via a metered dose inhaler or equivalent, and using a $\beta_{2}$ agonist as required. If, during the baseline study patients demonstrated a peak flow variation of at least $15 \%$ and recorded asthma symptoms for at least four of the last seven days, they were randomly allocated to one of the two treatment groups. Patients were excluded from the study if they were receiving maintenance oral corticosteroids or had received a short course of oral steroids in the six weeks before the start of the study or had received more than four short courses of oral steroids in the last year. Patients with a forced expiratory volume in one second $\left(\mathrm{FEV}_{1}\right)$ of less than $50 \%$ predicted were also excluded, as were those who had changed asthma therapy in the six weeks before the start of the study.

\section{TREATMENT}

During the two week baseline phase all patients were allowed to stay on their standard treatment which was BDP $400 \mu \mathrm{g}$ daily or equivalent. During the active treatment period patients received either salmeterol xinafoate $50 \mu \mathrm{g}$ twice daily via the four-place Diskhaler plus BDP $200 \mu \mathrm{g}$ twice daily via a metered dose inhaler or placebo twice daily via the four-place Diskhaler plus BDP $500 \mu \mathrm{g}$ twice daily via a metered dose inhaler. All patients were supplied with salbutamol for symptomatic relief throughout the study.

\section{MEASUREMENTS}

QOL was measured by questionnaire using the Living with Asthma Questionnaire, ${ }^{2}$ a 68 item questionnaire which can be scored either by its
11 domains or, following psychometric analysis subsequent to the original development of the scale, ${ }^{11}$ by its two constructs - Funtional limitation and Distress. The domains are Social/ leisure, Sport, Holidays, Sleep, Work and other activities, Colds, Mobility, Effects on others, Medication usage, Sex, and Dysphoric states and attitudes. The construct of Distress includes the majority of items in the domain of Dysphoric states and attitudes and some Medication usage items. Some of the Functional limitation items relate to specific problems - for example, going home early after a party - and others to the avoidance of activities - for example, avoiding other people with colds. No specific time frame is specified; patients are asked to respond according to how they are at the time assessed.

QOL was measured by structured diary using a specially constructed diary card that elicited information about QOL as well as symptoms and PEF. The diary was constructed on the basis of the content of existing QOL questionnaires, and there were four categories of problem: (a) paid employment, assessments, studying; (b) domestic jobs, housework, gardening, shopping, DIY; (c) visiting friends, leisure, sports, enjoyment; and (d) missed appointments, not getting things done. Subjects responded in the evening to all four problems on each day of diary completion using the following six categories: not applicable, no problems, one minor problem, a few minor problems, several major problems, as bad as I could imagine. Symptoms were assessed in the evening but patients also recorded in the morning whether they had been woken the previous night and taken relief medication during the day. PEF was recorded morning and evening.

Because some patients complete diaries retrospectively, ${ }^{12}$ they were instructed not to do so but to leave the space blank if they forgot on any day. The instructions were intended to legitimise forgetting and therefore to reduce the incentive to produce invalid data.

\section{PROCEDURE}

Patients completed the diary for the final seven days during a 14 day baseline period and for the first week of every month during the treatment period. The Living with Asthma Questionnaire was completed at the end of the baseline period and thereafter three monthly. We report data from the first three months of treatment of a longer trial. ${ }^{13}$

\section{DATA ANALYSIS}

Scoring

The Living with Asthma Questionnaire (LWAQ) was scored using its two construct subscales. ${ }^{14}$ Diary measures were scored as follows: problem incidence is the proportion of days when a problem was reported out of all days when either a problem or no problem was reported by the patient; problem severity is the average severity score on such days. Symptom incidence is the proportion of days out of all 
Table 1 Number of patients in each treatment group at start of study by sex and age $(n=426)$

\begin{tabular}{lcccccc}
\hline & \multicolumn{2}{c}{ Salmeterol/BDP } & & \multicolumn{2}{c}{ High dose BDP } \\
\cline { 2 - 3 } Age & Men & Women & & Men & Women \\
\hline $16-29$ & 23 & 9 & & 14 & 21 \\
$30-44$ & 24 & 31 & & 20 & 29 \\
$45-59$ & 31 & 47 & & 21 & 43 \\
$60+$ & 24 & 31 & & 30 & 28 \\
Total & 102 & 118 & & 85 & 121 \\
\hline
\end{tabular}

Table 2 Baseline average values for diary variables

\begin{tabular}{lccccc}
\hline & \multicolumn{2}{l}{ Salmeterol/BDP } & & \multicolumn{2}{l}{ High dose BDP } \\
\cline { 2 - 3 } & Mean & Median & & Mean & Median \\
\hline Morning PEF & 349.0 & 337.1 & & 338.8 & 339.2 \\
Evening PEF & 377.8 & 371.4 & & 369.1 & 368.3 \\
Diurnal variation & 0.15 & 0.12 & & 0.15 & 0.11 \\
Problem incidence & 0.56 & 0.60 & & 0.52 & 0.50 \\
Problem severity & 1.39 & 1.00 & & 1.26 & 0.80 \\
Night wakenings & 0.40 & 0.33 & & 0.35 & 0.17 \\
Symptom incidence & 0.87 & 1.00 & & 0.87 & 1.00 \\
Symptom severity & 1.48 & 1.50 & & 1.47 & 1.43 \\
\hline
\end{tabular}

PEF = peak expiratory flow.

Table 3 Number of days when a diary was completed for combined treatment groups

\begin{tabular}{|c|c|c|c|}
\hline \multicolumn{2}{|l|}{ Pre-treatment } & \multicolumn{2}{|l|}{ Post-treatment } \\
\hline $\begin{array}{l}\text { Number of days } \\
\text { completed }\end{array}$ & Number of patients & $\begin{array}{l}\text { Number of days } \\
\text { completed }\end{array}$ & Number of patients \\
\hline $\begin{array}{l}0 \\
1 \\
2 \\
3 \\
4 \\
5 \\
6 \\
7 \\
8 \text { or more }\end{array}$ & $\begin{array}{r}8 \\
3 \\
2 \\
5 \\
11 \\
18 \\
171 \\
204 \\
4\end{array}$ & $\begin{array}{l}0 \\
1-7 \\
8-15 \\
16-18 \\
19 \\
20 \\
21 \\
22 \text { or more }\end{array}$ & $\begin{array}{r}2 \\
98 \\
25 \\
14 \\
24 \\
153 \\
104 \\
6\end{array}$ \\
\hline
\end{tabular}

The protocol specified 7 days pre-treatment and 21 days post-treatment. For both pre-treatment and post-treatment patients who completed one or more days are deemed to have submitted a valid diary for that period.
valteatment patients
Statistical tests

The variables in this study consisted of two questionnaire QOL measures, five diary QOL or symptom measures, and three respiratory function measures - all 12 variables being observed during baseline and treatment periods. The baseline data are of mixed type. Some variables appear normally distributed - for example, some respiratory function indicators and the questionnaire constructs - while others are best treated as ordered categorical - for example, most diary measures and those questionnaire domain variables which are formed from very small subsets of questionnaire items. Diary QOL and symptom score analysis introduces a problem of statistical interpretation not found in diary physiological measures. Some patients scored at the extremes during the baseline period and remained at the same extreme during the treatement period - for example, no problems recorded on any day in both the baseline and treatment periods. It is impossible to tell whether these patients genuinely did not experience any change or whether the scale was insensitive in that instance due to floor or ceiling effects. Consequently these patients were excluded from the change analyses (longitudinal correlational analyses and efficacy analyses) as being invalid, as the inference that no change had taken place is uncertain. However, such patients were not excluded from baseline analyses (cross sectional correlations).

The various analyses use the valid subsets of the baseline and change variables and statistical tests have been selected to treat all variables in a similar manner. Thus, as a general rule, analyses which involve baseline data treat all variables as ordered categorical while analyses which involve only change data - that is, those examining treatment effects - use variables which may be regarded as fully ordinal at least. The analysis of diary validity (which involves baseline data) is by Goodman and Kruskal's gamma statistic for assessing the relationship between ordered variables in a contingency table (tables 6 and 7). The gamma statistic is measured on the same -1 to +1 scale as the more familiar higher level correlation coefficients and has the same qualitative interpretation. Mann-Whitney tests were used to compare the efficacy of the two treatments (table 9) and a paired $t$ test used to analyse change in respiratory function (table 8 ) as these change variables have higher levels of measurement. the absolute difference between the scores before and after treatment.

Data validity

Statistical tests were carried out on an intention to treat basis for valid data. Valid LWAQ questionnaires required an answer to at least 59 of the 68 items. Valid diary entries were on a variable basis; if a variable was marked for one or more days then that variable was deemed valid for that patient. However, if no mark was made on the diary record for a variable during the time period analysed, that variable was considered invalid.

\section{Results}

\section{SUBJECT POPULATION}

Sample size, age, and sex of the study population are shown in table 1 , and baseline diary values are shown in table 2 . Not all patients completed diaries for the full seven days before treatment and 21 days after treatment, and the number of diary days completed is shown in table 3. For some patients the seventh day before treatment coincided with the first day of treatment, and for these patients the seventh day was discounted so that a maximum of six 
Table 4 Number of patients completing valid diaries (any section) and questionnaires throughout the study

\begin{tabular}{llll}
\hline & Pre-treatment & Post-treatment & $\begin{array}{l}\text { Pre-treatment and } \\
\text { post-treatment }\end{array}$ \\
\hline Diary & 418 & 424 & 418 \\
Questionnaire & $(215: 203)$ & $(219: 205)$ & $(215: 203)$ \\
Both diary and & 378 & 295 & 276 \\
questionnaire & $(193: 185)$ & $(155: 140)$ & $(142: 134)$ \\
\hline
\end{tabular}

Numbers in parentheses show (salmeterol/BDP:high dose BDP).

Table 5 Number of patients completing valid problem sections of diary and questionnaires throughout the study

\begin{tabular}{llll}
\hline & Pre-treatment & Post-treatment & $\begin{array}{l}\text { Pre-treatment and } \\
\text { post-treatment }\end{array}$ \\
\hline Diary & 408 & 423 & 408 \\
Questionnaire & $(210: 198)$ & $(218: 205)$ & $(210: 198)$ \\
Both diary and & 378 & 295 & 276 \\
questionnaire & $(193: 185)$ & $(155: 140)$ & $(142: 134)$ \\
\hline
\end{tabular}

Numbers in parentheses show (salmeterol/BDP:high dose BDP).

Table 6 Cross sectional correlations between questionnaire, diary, and respiratory function measures

\begin{tabular}{|c|c|c|c|c|c|}
\hline & \multicolumn{2}{|c|}{ Questionnaire } & \multicolumn{3}{|c|}{ Respiratory function } \\
\hline & $\begin{array}{l}\text { Functional } \\
\text { limitation }\end{array}$ & Distress & $\begin{array}{l}\text { Morning } \\
P E F\end{array}$ & $\begin{array}{l}\text { Evening } \\
P E F\end{array}$ & $\begin{array}{l}\text { Diurnal } \\
\text { variation }\end{array}$ \\
\hline \multicolumn{6}{|l|}{ Diary: } \\
\hline Problem incidence & $0.414^{*}$ & $0 \cdot 296^{*}$ & -0.086 & -0.091 & 0.032 \\
\hline Problem severity & $0.492^{*}$ & $0.328^{*}$ & $-0.140 \dagger$ & $-0.133 t$ & -0.020 \\
\hline Night wakening & $0.421^{*}$ & $0.380^{*}$ & $-0.287^{*}$ & $-0.223^{*}$ & $-0.155 \ddagger$ \\
\hline Symptom incidence & $0.379^{*}$ & $0.296^{*}$ & $-0 \cdot 140 \ddagger$ & -0.071 & -0.044 \\
\hline Symptom severity & $0.387^{*}$ & $0 \cdot 328^{*}$ & $-0.170 t$ & $-0 \cdot 143 \ddagger$ & -0.070 \\
\hline \multicolumn{6}{|l|}{ Respiratory function: } \\
\hline Morning PEF & $-0.341^{*}$ & $-0 \cdot 137 \dagger$ & & & \\
\hline Evening PEF & $-0.350^{*}$ & $-0.137 \dagger$ & & & \\
\hline Diurnal variation & $-0 \cdot 106$ & $-0 \cdot 120 \ddagger$ & & & \\
\hline
\end{tabular}

${ }^{*} \mathrm{p}<0.001 ; \nmid \mathrm{p}<0.01 ; \ddagger \mathrm{p}<0.05$.

Table 7 Longitudinal correlations between questionnaire, diary, and respiratory function measures

\begin{tabular}{|c|c|c|c|c|c|}
\hline & \multicolumn{2}{|c|}{ Questionnaire } & \multicolumn{3}{|c|}{ Respiratory function } \\
\hline & $\begin{array}{l}\text { Functional } \\
\text { limitation }\end{array}$ & Distress & $\begin{array}{l}\text { Morning } \\
P E F\end{array}$ & $\begin{array}{l}\text { Evening } \\
P E F\end{array}$ & $\begin{array}{l}\text { Diurnal } \\
\text { variation }\end{array}$ \\
\hline Diary: & & & & & \\
\hline $\begin{array}{l}\text { Problem incidence } \\
\text { Problem severity } \\
\text { Night wakening } \\
\text { Symptom incidence } \\
\text { Symptom severity }\end{array}$ & $\begin{array}{l}0.376 \dagger \\
0.376 \dagger \\
0.379 \ddagger \\
0.172 \\
0.363 \dagger\end{array}$ & $\begin{array}{r}-0.007 \\
0.065 \\
0.139 \\
-0.097 \\
0.132\end{array}$ & $\begin{array}{l}0 \cdot 305 \dagger \\
0 \cdot 257 \ddagger \\
0 \cdot 208 \\
0 \cdot 500^{*} \\
0 \cdot 518^{*}\end{array}$ & $\begin{array}{l}0 \cdot 272 \ddagger \\
0 \cdot 242 \ddagger \\
0 \cdot 344 \ddagger \\
0 \cdot 283 \ddagger \\
0 \cdot 396^{*}\end{array}$ & $\begin{array}{r}-0 \cdot 147 \\
-0.139 \\
0 \cdot 178 \\
0 \cdot 109 \\
0.071\end{array}$ \\
\hline $\begin{array}{l}\text { Respiratory function: } \\
\text { Morning PEF } \\
\text { Evening PEF } \\
\text { Diurnal variation }\end{array}$ & $\begin{array}{r}0.005 \\
-0.203 \\
0.006\end{array}$ & $\begin{array}{r}0.143 \\
-0.149 \\
0.153\end{array}$ & & & \\
\hline
\end{tabular}

${ }^{*} \mathrm{p}<0.001 ; \dagger \mathrm{p}<0.01 ; \ddagger \mathrm{p}<0.05$.

Table 8 Difference between PEF on baseline days when patients had (a) no symptoms, (b) symptoms but no problems, (c) symptoms and problems

\begin{tabular}{lccc}
\hline $\begin{array}{l}\text { Difference between days on which } \\
\text { the following were recorded }\end{array}$ & Morning PEF & Evening PEF & Diurnal variation \\
\hline Symptoms $v$ no symptoms & & & \\
Mean & & & \\
n & -1.33 & -0.37 & 0.002 \\
p & 62 & 61 & 61 \\
Problems $v$ symptoms & & 0.92 \\
Mean & 0.72 & & \\
n & -4.71 & -6.65 & 0.004 \\
p & 206 & 205 & 204 \\
\end{tabular}

aymptoms but no problems - no symptoms.

bymptoms and problems - symptoms but no problems. days was recorded for a fully completed diary card; $89 \%$ of patients completed at least six days in the pretreatment diary. The incomplete diaries in the post-treatment period resulted partially from the 91 withdrawals (45 BDP/ salmeterol and 46 high dose BDP) that took place between the onset of treatment and the third month of treatment. Of those who attended the end visit at three months, $75 \%$ of patients completed diaries on at least 20 days.

Only patients who completed no days for a variable were deemed to have submitted invalid diaries for that variable. Tables 4 and 5 show the number of patients completing valid questionnaires and diaries for any diary entry and for any entry in the QOL (problem) section. A small number of patients completed the PEF section but not the QOL section. Completion rates were higher for diaries than questionnaires; questionnaires tending not to be completed at all rather than partially completed.

CORRELATIONS OF THE QOL DIARY WITH OTHER MEASURES

Table 6 shows the cross sectional correlations (at baseline) between the LWAQ subscale scores, the QOL component of the diary (Problem incidence and Problem severity), and the symptom component of the diary (Night wakenings, Symptom incidence, and Symptom severity). All of the QOL diary symptom measures correlated more strongly with the Functional limitation subscale than the Distress subscale, though all correlations were significant at $\mathrm{p}<0.001$. We also examined the correlations between QOL diary measures and the LWAQ domain subscale scores, and the size of these correlations was consistent with expectation - for example, the Sleep domain correlated 0.64 with diary assessed Night wakenings. In addition, table 6 shows the cross sectional correlations between respiratory function measures and QOL measured by the LWAQ, QOL measured by the diary, and symptoms. As predicted, ${ }^{10}$ the Functional limitation subscale score of the LWAQ correlated more strongly with PEF than the Distress subscale. PEF correlated less well with diary assessed QOL than with the Functional limitation subscale of the LWAQ. Diurnal variation had nonsignificant cross sectional correlations with all QOL and almost all symptom assessments.

Table 7 shows the longitudinal correlations between QOL as measured by the LWAQ, the diary QOL and symptom assessments, and respiratory function. About $25 \%$ of the sample entered into the cross sectional analysis had either ceiling or floor effects on the diary measures - that is, no change over all days recorded throughout the trial - and so were not included in the longitudinal analysis. Numbers of patients entered into the longitudinal diary measures were, for the following variables: symptoms: 286 (153 salmeterol/BDP and 133 high dose BDP); night wakenings: 254 (130 salmeterol/BDP and 124 high dose BDP); problems: 309 (156 salmeterol/BDP and 152 high dose BDP). Inclusion of patients with 
Table 9 Medians and comparative efficacy of salmeterol/BDP and high dose BDP on diary and questionnaire measures

\begin{tabular}{|c|c|c|c|c|c|c|c|}
\hline & \multicolumn{3}{|c|}{ Salmeterol/BDP } & \multicolumn{3}{|c|}{ High dose $B D P$} & \multirow[t]{2}{*}{$p$} \\
\hline & Baseline & Treatment & Change $^{\mathrm{a}}$ & Baseline & Treatment & Change $^{\mathrm{a}}$ & \\
\hline \multicolumn{8}{|l|}{ Questionnaire } \\
\hline Functional limitation & 0.95 & 0.85 & -0.04 & 0.94 & 0.85 & -0.06 & NS \\
\hline Distress & 0.63 & 0.56 & 0.00 & 0.61 & 0.50 & 0.00 & NS \\
\hline \multicolumn{8}{|l|}{ Diary } \\
\hline Problem incidence & 0.67 & 0.42 & $-0 \cdot 18$ & 0.50 & 0.35 & $-0 \cdot 11$ & $0.02 *$ \\
\hline Problem severity & $1 \cdot 25$ & 0.80 & $-0 \cdot 29$ & 1.00 & 0.90 & $-0 \cdot 14$ & $0.03 *$ \\
\hline Night wakenings & 0.50 & 0.24 & $-0 \cdot 20$ & 0.43 & $0 \cdot 27$ & -0.14 & $0.02 *$ \\
\hline Symptom incidence & 1.00 & 0.52 & -0.35 & 0.86 & 0.53 & -0.26 & NS \\
\hline Symptom severity & 1.50 & 0.95 & $-0 \cdot 42$ & $1 \cdot 43$ & 1.00 & -0.36 & NS \\
\hline
\end{tabular}

ceiling and floor effects in the longitudinal correlational analyses reduced the size of the correlations, though significance levels remained broadly the same. The correlations between QOL diary assessments and Functional limitation were significant; those between QOL diary assessments and Distress were not. The QOL diary change measures were significantly related to change in respiratory function but neither of the QOL questionnaire subscales correlate significantly with respiratory function change. (Statistical note: we compared different ways of calculating proportion of problem and symptom days, and the procedure described in the methods section provides the best correlational results as well as appearing the most justifiable $a$ priori.)

\section{PEF ON DAYS WHEN PATIENTS REPORT} SYMPTOMS AND PROBLEMS

Table 8 shows the difference between mean PEF on days when patients did and did not report symptoms (no patients reported problems in the absence of symptoms) during the baseline period. Sixty two (for morning) and 61 (for evening) patients completed PEF on at least one day when they had no symptoms as well as at least one day when they had symptoms but no problems during the baseline period. For each of these patients mean PEF was calculated for the symptom-free days and for the symptom but no problem days. There was no significant difference in mean PEF between symptom and symptom-free days. Also shown in table 8 are the differences in mean PEF for days when patients had symptoms but no problems and days when they had symptoms and problems $(n=206$ for morning and 205 for evening PEF readings). Days when patients had problems were associated with significantly lower PEF values than when they had only symptoms, both for morning and evening PEF but not for diurnal variation. Thus, reports of problems provide a more accurate predictor of low PEF than reports of symptoms.

EFFICACY OF THE TWO TREATMENTS

As a separate analysis ${ }^{13}$ of this study has shown that treatment with salmeterol/BDP produced better lung function values than high dose BDP, in the final stage of the analysis we compared the change in QOL and symptoms of the two treatment groups and these data are shown in table 9. There were no significant differences between the two treatment groups for either of the two LWAQ subscales or symptom scores. Excluding the no change subjects for the purpose of the diary analysis (sample sizes are the same as for longitudinal correlational analysis above), salmeterol/BDP produced significantly better change for problem incidence $(p=0.02)$, problem severity $(\mathrm{p}<0.05)$, and night wakenings $(p=0 \cdot 02)$. Table 9 shows the mean values for these patients, but if those patients exhibiting floor and ceiling effects are included in the analysis, the significance levels are slightly reduced $(p=0.02, p=0.05$, and $p=<0.05$, respectively), though still significant.

\section{Discussion}

Responsiveness to change is an important characteristic of a QOL instrument when it is used in a clinical trial. ${ }^{89}$ Although the Living with Asthma Questionnaire has been shown in two other studies ${ }^{1415}$ to be able to detect treatment differences between salmeterol and placebo, we found in this study that it was unable to detect differences between salmeterol/BDP and high dose BDP. It may be that the questionnaire is able to detect improvement compared with no improvement but not able to distinguish different degrees of improvement. By contrast, the QOL structured diary was able to detect differences in level of improvement between salmeterol/BDP and high dose BDP.

Although diaries are an established methodology for assessment of asthma symptoms and $\mathrm{PEF}^{16}$ the issue of patient compliance and validity remains. In this study patients were never required to complete a diary for more than seven days at a stretch. We found that patient compliance was good even though they were instructed to leave days blank if they forgot. Level of retrospective completion cannot be computed from paper and pencil diaries, though varying estimates have been obtained from electronic recordings in other studies. ${ }^{1217}$ We found that diaries, in contrast to questionnaires, suffer from floor and ceiling effects and about $25 \%$ of patients showed no change in problem incidence throughout the entire study. The inclusion of such patients in longitudinal analysis is questionable as it is unclear whether no change really means no change or that the instrument is out of range for these patients. Our longitudinal analyses excluded such patients for this reason, and this decision 
was consistent with the finding that inclusion of no change patients reduced the size of correlations and efficacy. Clearly, the existence of floor and ceiling effects in a measuring instrument represents an important limitation, and this finding suggests that future use of QOL diaries in clinical trials may require careful attention to patient selection on QOL grounds rather than on only physiological grounds. For example, patients who never report QOL problems are unlikely to change from this zero level of problem incidence when treated with superior medication irrespective of lung function, and the inclusion of such patients in a QOL trial is therefore inappropriate. $\mathrm{Al}$ ternatively, it may be possible to develop diary methodology so that floor and ceiling effects are less common.

Examination of the correlational data shows that, in general, the questionnaire had superior cross sectional correlations and the diary had superior longitudinal correlations with respiratory function. It would appear therefore that a QOL diary has a useful role in evaluating clinical trials but it is not a substitute for questionnaires which are more comprehensive and provide better cross sectional comparisons. The poor cross sectional correlations between the diaries and absolute PEF values suggest that patients have idiosyncratic ways of responding to diaries which, while consistent over time, provide a poor measure of cross sectional disease severity.

There was good convergent validity between the diary and questionnaire and, in particular, the Functional limitation subscale of the questionnaire. The Functional limitation subscale (which in a previous study was found to be more sensitive to change than the Distress subscale ${ }^{14}$ ) includes two kinds of items in several domains: those describing specific problems and those describing the avoidance of activities of which the diary assesses only the former. The high convergent validity (good cross sectional and longitudinal correlations) between Functional limitation and diary assessed problems is consistent with the diary assessing specific problems arising from the exacerbation of asthma.

The diary does not appear to be a particularly good measure of distress, and the additional information contained in the problems severity score in contrast to the problems incidence score did not add anything either to the correlations or responsiveness to change. It appears that rating the severity of a problem provides no more useful information than simply indicating whether a problem has occurred or not; however, this conclusion must be treated cautiously as most problems recorded in this study were minor rather than severe. Furthermore, as this was the first QOL diary to be used in a clinical trial it is yet to be determined whether other types of diary format lead to similar conclusions.

The mean PEF on days when patients reported only symptoms and days when they reported problems provides useful information about how diary reported problems differ from diary reported symptoms. We found that on some days patients reported no symptoms or problems, some days they reported symptoms and no problems, and some days they reported symptoms and problems (they never reported problems and no symptoms). The existence of symptoms alone was not associated with a lower PEF compared with symptom-free days, confirming the generally poor relationship between symptomatology and PEF. ${ }^{18}$ However, mean PEF was significantly lower on days when patients had problems compared with when they had symptoms and no problems. It would seem that patients report problems during the troughs of a PEF graph, whereas they report symptoms over a broader spectrum of values in a PEF graph. Diary-reported problems were more responsive to longitudinal change than diary-reported symptoms (but not night time symptoms). This is either because problems are a more responsive subjective measure than symptoms or because of treatment effects: it may be that salmeterol/BDP leads to a greater reduction in the more severe PEF troughs compared with the less severe PEF troughs than high dose BDP. In any case it would seem that problem diaries provide useful additional information compared with symptom diaries and can play a useful part in clinical trials.

In conclusion, patients seemed to find a structured QOL diary acceptable and completion rates were high under circumstances where patients never had to complete a diary for more than seven days in one stretch. Diary assessed QOL is a valid and responsive technique for measuring one component of QOL, but questionnaires provide a broader and more sensitive cross sectional measure. The major weakness with QOL diaries is that for some patients they exhibit floor and ceiling effects, and for these patients diaries are an invalid measure of change. Care must therefore be taken in clinical trials either to select out such patients or to develop diaries that are less prone to floor and ceiling effects.

QOL diaries measure patient perceived problems, and the patient's subjective awareness of problems is not the same as their awareness of symptoms. Diary recorded problems provide a better measure of the troughs in a PEF graph and we found them to be more sensitive to treatment changes than symptoms. Thus, diary reported QOL problems should be assessed in clinical trials where subjective reports of patients are an important outcome measure.

The authors thank the general practitioners who took part in the study and members of the Allen and Hanburys study team.

1 Jones PW, Quirk FH, Baveystock CM, Littlejohns P. A selfcomplete measure of chronic airflow limitation - the St George's Respiratory Questionnaire. Am Rev Respir Dis 1992;145:1321-7.

2 Hyland ME, Finnis S, Irvine SH. A scale for assessing quality of life in adult asthma sufferers. $\mathcal{f}$ Psychosom Res quality of life in

3 Juniper EF, Guyatt GH, Epstein RS, Ferrie PJ, Jaeschke R, Hiller TK. Evaluation of impairment of health related quality of life in asthma: development of a questionnaire for use in clinical trials. Thorax 1992;47:76-83.

4 Marks GB, Dunn SM, Woolcock AJ. A scale for the measurement of quality of life in adults with asthma. $\mathcal{f}$ Clin Epidemiol 1992;45:461-72.

5 Creer TL, Wigal JK, Kotses H, McConnaughy K, Winder JA. A life activities questionnaire for adult asthma. $f$ Asthma 1992;29:393-9.

6 Raphael KG, Cloitre M, Dohrenwend BP. Problems of recall and misclassification with checklist methods of measuring 
stressful life events. Health Psychol 1992;10:62-74

7 DeLongis A, Coyne JC, Dakof G, Folman S, Lazarus RS Relationship of daily hassles, uplifts, and major life events to health status. Health Psychol 1982;1:119-36.

8 Guyatt GH, Kirshner B, Jaeschke R. Presentation: Measuring health status: what are the necessary measurement properties. 7 Clin Epidemiol 1992;45:1341-5.

9 Kroperties. F Clin Epidemiol 1992;45:1341-5. assessing health indices. $\mathcal{F}$ Chron Dis 1985;38:27-36.

10 Hyland ME. A reformulation of quality of life for medical science. Qual Life Res 1992;1:267-72.

11 Hyland ME, Kenyon CAP, Jacobs P. Evidence for problem and evaluation constructs of the Living with Asthma Questionnaire: a multinational psychometric comparison. Qual Life Res 1994;3:80.

12 Hyland ME, Kenyon CAP, Allen R, Howarth P. Diary keeping in asthma: comparison of written and electronic methods BMF 1993;306:487-9.

13 Greening AP, Ind PW, Northfield M, Shaw G. Added salmeterol versus higher-dose corticosteroid in asthmatic patients with symptoms on existing inhaled corticosteroid. Lancet 1994;344:219-24.

14 Hyland ME, Kenyon CAP, Jacobs P. Sensitivity of quality of life domains and constructs to longitudinal change in a clinical trial comparing salbutamol with placebo in asthmatics. Qual Life Res 1994;3:121-6.

15 Palmer JBD, Hyland ME. Salmeterol in clinical practice: comparator and safety studies, quality of life studies. Eur Respir f 1991;1:301-3.

16 Society of Pharmaceutical Medicine Expert Panel. Clinical development of drugs against asthma. Problems of com pliance. F Pharm Med 1993;3:217-22

17 Chowienczyk PJ, Parkin DH, Lawson CP, Cochrane GM Do asthmatic patients correctly record home spirometry measurements? BMF 1994;307:1618.

18 Kendrick AH, Higgs CMB, Whitfield MJ, Laszlo G. Accuracy of perception of severity of asthma: patients treated in general practice. BMF 1993;307:422-4. 